\title{
THE EFFECTIVENESS OF FRAUD TRIANGLE ON DETECTING FRAUDULENT FINANCIAL STATEMENT: USING BENEISH MODEL AND THE CASE OF SPECIAL COMPANIES
}

\author{
Aprillia \\ Orlin Cicilia \\ Rafaela Pertiwi Sergius \\ mm_lea88@ymail.com \\ (Universitas Trisakti Jakarta)
}

\begin{abstract}
Fraudulent financial statement is a serious problem and to be a threat to stakeholders, especially for investor. The thing is happened because there is illegal action done intentionally, such as disclosing financial information that doesn't match with the real condition. The purpose of this research is to acquire a effectiveness of empirical proof of fraud triangle consisting of Pressure, Opportunity, and Rationalization in detecting financial statement fraud that are indicated by using Beneish Model. The sample of this research consists of 39 companies are indicated doing fraud and 57 companies aren't indicated doing fraud listing at BEI (Bursa Efek Indonesia) in 2012 - 2014. Test of this research uses logistic regression method. Based on the result and conclusion, this research shows that opportunity (independent commissioner ownership) has significant effect to fraudulent financial statement while pressure (AGROW), financial target (ROA), and rationalization (Total accrual) don't have significant effect to fraudulent financial statement.
\end{abstract}

Keywords: Fraudulent Financial Statement, Fraud Triangle, Beneish Model, Logistic Regression, Go Public Infrastructure Company

\section{PENDAHULUAN \\ Latar Belakang}

Tekanan ekonomi global menimbulkan ancaman bagi pelaku usaha dan para pengambil keputusan. Mereka sangat memerlukan laporan keuangan sebagai informasi untuk melihat seberapa mampu perusahaan dapat bertahan ditengah tekanan global. Gambaran dari informasi tersebut menjadi acuan untuk menetapkan strategi selanjutnya. Melihat dari pentingnya laporan keuangan sebagai alat pengambil keputusan, maka sangat perlu diperhatikan bahwa laporan keuangan harus memiliki kualitas tinggi dan bersih dari adanya unsur dan indikasi fraud, Sebab kecurangan laporan keuangan merupakan masalah yang serius dan menjadi ancaman bagi pihakpihak eksternal perusahaan, khususnya bagi investor. Hal itu dikarenakan adanya tindakan ilegal yang secara sengaja dilakukan, seperti mengungkapkan informasi keuangan yang tidak sesuai dengan keadaan yang sebenarnya terjadi.

Di sisi lain, perusahaan selalu memiliki banyak cara dalam menutupi tindakan fraud yang dilakukan. Sebab, perusahaan biasanya memiliki suatu tujuan khusus dalam melakukan tindakan tersebut, seperti ingin mendapatkan keuntungan yang sebanyak-banyaknya dan mendapatkan kepercayaan dari para pihak eksternal perusahaan. Di dalam praktik untuk mendapatkan kepercayaan dari pihak eksternal, biasanya perusahaan akan melakukan tindakan fraud yang mengarah pada laporan 
keuangan yang dimilikinya. Laporan keuangan tersebut akan dibuat sedemikian bagus atau layak di mata investor dalam membuat keputusan dengan melakukan perataan laba atau manajemen laba. Dari hal inilah, isi pada laporan keuangan yang akan disajikan oleh perusahaan tersebut biasanya akan memuat hal-hal yang tidak sesuai dengan kenyataan yang sebenarnya. Padahal, menurut Fitrawansyah (2014:9), laporan keuangan menjadi tidak seperti yang seharusnya (tidak mewakili kenyataan), tergolong kelompok fraud terhadap laporan keuangan.

Kasus nyata mengenai kecurangan laporan keuangan, terjadi pada PT. Inovisi Intracom Tbk (INVS), di mana sejak awal periode 2015 perdagangan saham Inovisi telah disuspensi oleh Bursa Efek Indonesia (BEI). Seperti yang dilansir dalam detik finance tertulis bahwa setelah mensuspensi saham INVS, Otoritas bursa pun melakukan penelaahan terhadap laporan keuangan perusahaan kuartal III-2014.Dari situ diketahui ada delapan poin dalam laporan keuangan Inovisi yang mencurigakan. Pernyataan tersebut secara tidak langsung identik dengan tujuan dilakukannya penelitian ini, yaitu untuk memberikan gambaran tentang laporan keuangan yang berkualitas atau tidak dengan mengetahui pengaruh yang terjadi antara fraud triangle dengan laporan keuangan yang telah teridikasi mengandung unsur fraud yakni dengan mengetahui terdeteksinya banyak perusahaan yang melakukan manajemen laba yang tidak wajar atau menyimpang dari prinsip akuntansi yang berlaku.

Motivasi peneliti dalam melakukan penelitian ini adalah ingin mengetahui seberapa efektif pengaruh fraud triangle dalam mendeteksi kecurangan laporan keuangan (fraudulent financial statement) yang dilakukan karena penyimpangan dari manajemen laba yang dilakukan perusahaan. Penelitian ini memiliki keunikan dalam pengukuran laporan keuangan yang terindikasi fraud yakni dengan mencari index beneish yaitu suatu index yang memberikan gambaran tolak ukur manajemen laba yang mengarah kepada manipulasi laba yang tidak wajar. Pada umumnya, perataan laba atau manajemen laba merupakan suatu tindakan yang mengarah pada manipulasi laba yang ada di dalam laporan keuangan. Namun, menurut Ahmad Berkouli (2007:198), pemikiran umum di belakang perataan laba adalah bahwa manajer mungkin mengambil tindakan yang menurunkan pelaporan laba pada saat laba tinggi. Hal ini dimungkinkan baik melalui fleksibilitas yang diperbolehkan dalam prinsip akuntansi berlaku umum maupun perubahan-perubahan yang disengaja di dalam operasional laba. Dari pernyataan di atas, perusahaan biasanya akan memanfaatkan perlakuan tindakan perataan laba tersebut sebagai peluang dalam membuat laporan keuangan menjadi bagus di mata para pihak eksternal perusahaan, khususnya investor dengan cara yang secara tidak langsung menyimpang dari prinsip akuntansi yang berlaku.

Selain itu, penelitian ini juga berbeda dari penelitian yang telah ada dikarenakan peneliti memfokuskan obyek penelitian pada perusahaan-perusahaan publik yang bergerak pada sektor industri yang sering terlibat dalam proyek pengadaan di pemerintahan yakni konstruksi, infrastruktur, transportasi dan telekomunikasi. Hal ini tidak terlepas karena mengikuti perkembangan berita yang relevan, di mana pada akhir-akhir ini sering sekali industri yang terlibat dalam proyek pengadaan dipemerintahan harus berurusan dengan KPK (Komisi Pemberatasan Korupsi), seperti proyek Hambalang.

Berdasarkan data Lembaga Kebijakan Pengadaan Barang dan Jasa Pemerintah (LKPP), banyak seķtor industri (seperti konstruksi, infrastruktur, transportasi dan telekomunikasi) diklasifikan masuk sebagai daftar hitam. Lalu, berita dari radarbanten 
juga mengungkapkan bahwa kontraktor yang menggarap pembangunan gedung DPRD Tangerang Selatan pun telah di blacklist oleh LKPP. Melihat dari fakta yang diungkapkan tersebut, maka peneliti menganggap layak apabila analis, investor ataupun stakeholders mengkritisi industri yang bergerak di sektor-sektor tersebut dikarenakan tidak menutup kemungkinan jika dalam beroperasi saja sudah melakukan tindakan pelanggaran hukum, maka dapat dipastikan dalam menyusun laporan keuangan, laporan tersebut akan mengandung unsur fraud yang semakin lama apabila dibiarkan akan semakin besar.

Dari uraian yang telah dijabarkan sebelumnya, motivasi, keunikan penelitian, data dari LKPP, maka peneliti mengangkat judul pada penelitian ini, yaitu "The Effectiveness Of Fraud Triangle On Detecting Fraudulent Financial Statement: Using Beneish Model And The Case Of Special Companies".

\section{Rumusan Masalah}

Berdasarkan latar belakang yang telah diungkapkan di atas, rumusan masalah atas penelitian ini adalah, (1) Apakah asset growthmemiliki pengaruh yang signifikan terhadap kecurangan laporan keuangan; (2) Apakah ROA memiliki pengaruh yang signifikan terhadap kecurangan laporan keuangan; (3) Apakah persentase komisarisindependen memiliki pengaruh yang signifikan terhadap kecurangan laporan keuangan; (4) Apakah total accrual memiliki pengaruh yang signifikan terhadap kecurangan laporan keuangan.

\section{KAJIAN PUSTAKA}

AICPA mendefinisikan kecurangan laporan keuangan sebagai hal yang disengaja, salah saji atau penghilangan fakta-fakta material, atau data akuntansi yang menyesatkan dan, bila dianggap dengan semua informasi yang telah dibuat, akan menyebabkan pembaca mengubah penilaian atau keputusannya. Dalam ACFE sendiri kecurangan laporan keuangan dibedakan menjadi dua hal yakni,fraud dalam menyusun laporan keuangan yang terdiri dari asset/revenue overstatements dan asset/revenue understatements) dan fraud dalam menyusun laporan non-keuangan.

Kecurangan menyusun laporan keuangan merupakan tindakan yang dilakukan oleh pejabat atau eksekutif suatu perusahaan untuk menutupi kondisi keuangan yang sebenarnya dengan melakukan rekayasa keuangan (financial engineering) dalam penyajian laporan keuangannya untuk memperoleh keuntungan atau mungkin dapat dianalogikan dengan istilah window dressing (Nugraha dan Henny,02:2015).

Fraud Triangle dijelaskan Cressey (1953) dalam dalam Skousen et al (2009) menyatakan bahwa kecurangan secara umum mempunyai tiga sifat umum. Menurut Turner et al, 2003 dalam Daljono (02:2013) Fraudtriangle terdiri dari tiga kondisi yang umumnya hadir pada saat fraud terjadi yaitu pressure, opportunity, dan rationalization.

Berdasarkan SAS No.99 dalam Sukirman dan Sari (09:2013) faktor-faktor risiko kecurangan terkait kasus pelanggaran perusahaan terangkum dalam tabel dibawah ini:

\section{Tabel 2.1}


Faktor-Faktor risiko kecurangan

\begin{tabular}{l}
\hline \multicolumn{1}{c}{ KESEMPATAN } \\
\hline 1. Financial stability or \\
profitability is threatened by \\
economic, industry, or entity \\
operating \\
conditions:
\end{tabular}

Related-party transactions beyond ordinary

A strong financial presence or ability to dominate a certain industry sector that allows the entity to dictate terms or conditions to suppliers or

Customers

Accounts based on significant estimates

Significant, unusual, or highly complex transactions

Significant operations across international borders environments and cultures Significant bank accounts in tax-haven jurisdictions

2. Excessive pressure exists for management to meet requirements of third parties:

Profitability/trend expectations

Need to obtain additional debt or equity financing

Marginal ability to meet exchange listing requirements or debt repayment or other debt covenant requirements

Likely poor financial results on significant pending

transactions

directors' personal financial situationis:
High degree of competition or declining profit margin

High vulnerability to rapid changes (i.e., technology, obsolescence, or interest rates)

Declines in customer demand

Operating losses

Recurring negative cash flows from operations

Rapid growth or unusual profitability

New accounting, statutory, or regulatory requirements

\section{Ineffective monitoring of} management allows:

Domination of management by a single person or small group

Ineffective board of directors or audit committee oversight

\section{There is a complex or unstable organizational} structure

Difficulty in determining the organization orindividuals that have control of company

Overly complex structure
RASIONALISASI

1.Attitudes/rationalizations

by board members,

management, or employees that allow them to engage in and/or justify fraudulent financial reporting

Ineffective communication implementation, support, or enforcement of ethics

Non-financial management's excessive participation in selection of accounting principles or the determining estimates

Known history of violations of securities laws or other laws

Excessive interest in maintaining or increasing stock price

Aggressive or unrealistic forecasts

Failure to correct known reportable conditions on a timely basis

Interest by management in employing inappropriate means to min. reported earnings for tax Recurring attempts by management to justify marginal or inappropriate accounting on the basis of materiality

Strained relationship with current or predecessor auditor

Frequent disputes with the current or predecessor auditor

Unreasonable demands on the auditor, such as unreasonable time constraints Restrictions on the auditor that inappropriately limit access

Domineering management behavior in dealing with the auditor 


\begin{tabular}{ll}
\hline $\begin{array}{l}\text { Significant financial interests } \\
\text { in the entity }\end{array}$ & $\begin{array}{l}\text { High turnover of senior } \\
\text { management, counsel, orboard } \\
\text { Significant performance based } \\
\text { compensation }\end{array}$ \\
$\begin{array}{l}\text { Personal guarantees of debts } \\
\text { 4. There is excessive } \\
\text { pressure on management or } \\
\text { operating personnel to meet } \\
\text { financial targets setup by } \\
\text { directors or management }\end{array}$ & $\begin{array}{l}\text { 4. Internal control deficient } \\
\text { Inadequate monitoring of } \\
\text { controls }\end{array}$ \\
& $\begin{array}{l}\text { High turnover rates or } \\
\text { employment of ineffective } \\
\text { accounting, internal audit, or } \\
\text { information technology staff } \\
\text { Ineffective accounting and } \\
\text { information systems }\end{array}$ \\
\hline
\end{tabular}

\section{Tekanan:}

1. Stabilitas

Keuangan

(AGROW)

2. Target Keuangan (ROA)

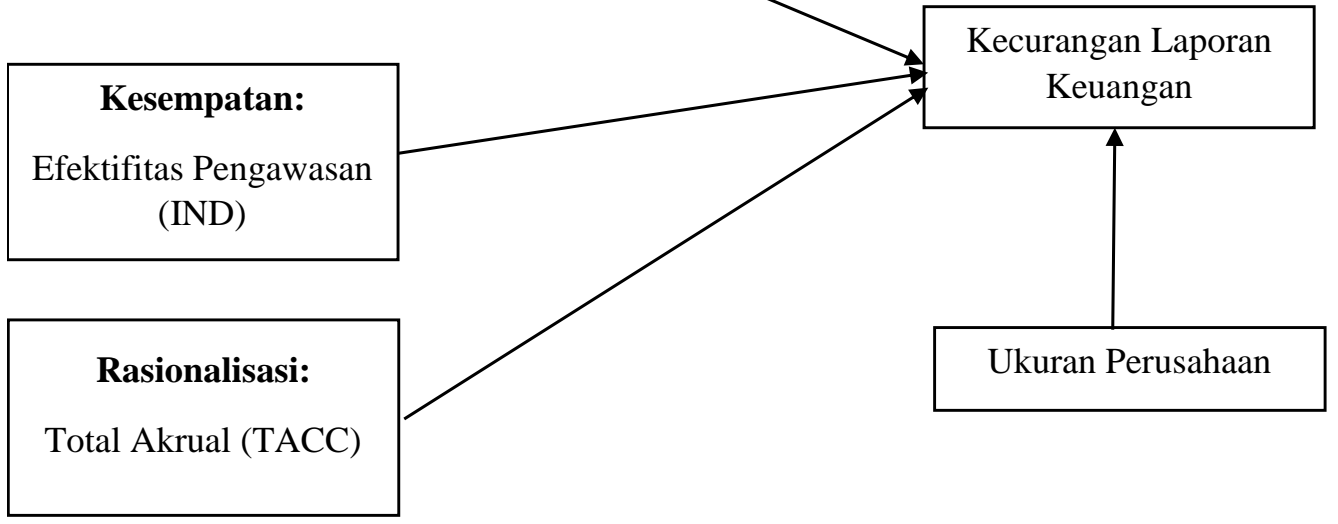

\section{Gambar 2.1}

Kerangka Pemikiran Teoritis

Stabilitas Keuangan merupakan gambaran mengenai stabil atau tidak suatu kondisi keuangan perusahaan. Manajemen akan selalu berusaha agar stabilitas keuangan suatu perusahaan selalu terlihat baik dengan melakukan berbagai cara dan strategi. Hal ini menciptakan suatu tekanan tersendiri bagi setiap manajemen terutama saat menghadapi situasi dimana kondisi keuangan perusahaan sedang terancam sehingga membuat manajemen terdorong untuk melakukan kecurangan dalam laporan keuangannya. Hal ini sesuai dengan SAS No.99 dalam Martantya dan Daljono ( 02:2013), ketika stabilitas keuangan terancam oleh keadaan ekonomi, industri, dan situasi entitas yang beroperasi, manajer menghadapi tekanan untuk melakukan financial statement fraud (Skousen et al. 2009).

Stabilitas keuangan dilihat dari seberapa besar tingkat pertumbuhan aset yang dimiliki perusahaan. Tingkat pertumbuhan aset yang bagus dapat menaikkan nilai perusahaan yang akan berdampak pada tingkat return yang akan diterima investor maupun bonus yang diterima oleh manajemen. Alasan tersebut seringkali manajemen 
terdorong untuk menjadikan laporan keuangan sebagai alat mereka menutupi kondisi stabilitas keuangan yang tidak sesuai harapan dengan melakukan fraud.

Dalam penelitian yang dilakukan oleh Skousen et. al. (2009) membuktikan bahwa adanya hubungan antara tingkat pertumbuhan aset perusahaan dengan kemungkinan terjadinya kecurangan laporan keuangan. Hal ini sesuai dengan penelitian Martantya dan Daljono (02:2013) yang menunjukkan bahwa pertumbuhan aset berpengaruh terhadap kemungkinan terjadinya kecurangan laporan keuangan. Berdasarkan uraian tersebut diperoleh hipotesis penelitian yakni:

$\mathrm{Ha}_{1}$ : Stabilitas Keuanganberpengaruh terhadap kecurangan laporan keuangan

Target keuangan yang diproksikan dengan ROA menunjukan tingkat pengembalian aset yang dimiliki oleh perusahan. Manajemen dalam praktiknya sering menetapkan target keuangan untuk tahun berjalan dan mendatang yang ingin dicapai berdasarkan ROA tahun sebelumnya. Seringkali manajemen menetapkan ROA yang terlampau tinggi agar mereka juga mendapat bonus yang tinggi tetapi dalam perjalanan tidak dapat terpenuhi sehingga menimbulkan tekanan yang mendorong manajemen memakai laporan keuangan sebagai alat menutupi kegagalan target mereka dengan melakukan fraud.

Dalam penelitian yang dilakukan oleh Nugraha dan Henny (02:2015) menunjukan bahwa return on asset memiliki pengaruh terhadap kecurangan laporan keuangan. Hasil yang sama juga terdapat dalam penelitian Diany dan Ratmono (03:2014). Hasil bahwa ROA berpengaruh terhadap kecurangan laporan keuangan juga dibuktikan oleh Martantya dan Daljono (02:2013) yang didukung Summers dan Sweeney (1998) melaporkan bahwa ROA antara fraud firm dan non - fraud firm secara signifikan berbeda (Skousen et al. 2009). Berdasarkan uraian tersebut diperoleh hipotesis penelitian yakni:

$\mathrm{Ha}_{2}$ : Target Keuangan berpengaruh terhadap kecurangan laporan keuangan.

Menurut Gunarsih dan Hartadi (2002) dalam Martantya dan Daljono (02:2013), Dewan komisaris secara luas dipercaya memainkan peranan penting khususnya dalam memonitor manajemen tingkat atas. Adanya dewan pengawas yang independen dianggap membuat keefektifan pengawasan perusahaan meningkat dan praktik kecurangan semakin diminimalisir. Pernyataan Standar Audit (PSA) no.70 dalam Nugraha dan Henny ( 02;2015) menunjukkan bahwa sebagian kecurangan laporan keuangan yang dapat timbul dari dominasi manajemen oleh seorang individu atau kelompok kecil, tanpa adanya pengendalian yang mengompensasi kondisi tersebut, seperti pengawasan oleh dewan komisaris atau komite audit. Oleh sebab itu, efektivitas pengawasan diproksi dengan rasio dewan komisaris independen (IND).

Hasil penelitian membuktikan bahwa kecurangan lebih sering terjadi pada perusahaan yang lebih sedikit memiliki anggota dewan komisaris eksternal (Skousen et al. 2009). Berdasarkan uraian tersebut diperoleh hipotesis penelitian yakni :

$\mathrm{Ha}_{3}$ : Efektivitas pengawasan berpengaruh terhadap kecurangan laporan keuangan.

Rasionalisasi yang diproksikan dengan Total Akrual (TACC) menggambarkan pembenaran atas tindakan atau sikap dalam melakukan praktik kecurangan. Terkait kecurangan yang berkaitan dengan laporan keuangan seringkali manajemen bersikukuh atas praktik akuntansi yang curang yang telah mereka lakukan dimana tercermin dari besarnya produk akrual yang tampak dalam laporan keuangan.

Secara umum, akrual merupakan produk akuntansi, yang dapat dianggap memiliki jumlah yang "relatif tetap" dari tahun ke tahun. Hal ini dikarenakan aturan akuntansi terkait juga tidak mengalami perubahan (Ardiyani dan Utaminingsih,2015). 
Rahayu (2009) dalam Ardiyani dan Utaminingsih,2015 mengatakan perubahan akrual yang terjadi merupakan hasil penggunaan kebijakan (discretion) manajemen yang berlebihan dan bila pada saat yang sama manajemen juga memiliki insentif/motif untuk memanipulasi laba maka perubahan yang terjadi dianggap sebagai bentuk manipulasi laba yang dilakukan manajemen. Berdasarkan uraian tersebut diperoleh hipotesis penelitian yakni :

Ha4: Rasionalisasi berpengaruh terhadap kecurangan laporan keuangan.

\section{METODE PENELITIAN}

\section{Variabel Dependen}

Variabel dependen yang digunakan dalam penelitian ini adalah kecurangan laporan keuangan. Pengukuran variabel ini menggunakan formula Beneish M-Score dalam Mahama (2015). Beneish Model ini menggunakan skala rasio dan memiliki batasan yang mejadi tolak ukur suatu perusahaan melakukan kecurangan pada laporan keuangannya. Menurut Warshavsky (2012), apabila hasil yang diperoleh dari model beneish lebih besar dari -2,22, maka perusahaan tersebut terindikasi melakukan manipulasi pada laporan keuangannya. Menurut Model Beneish dapat direpresentasikan sebagai berikut:

$$
\begin{aligned}
\mathrm{M}= & -4.84+0.920 \mathrm{DSR}+0.528 \mathrm{GMI}+0.404 \mathrm{AQI}+0.892 \mathrm{SGI}+0.115 \\
& \text { DEPI }-0.172 \mathrm{SGAI}+4.679 \mathrm{ACCRUALS}-0.327 \mathrm{LEVI}
\end{aligned}
$$

Dalam Mahama (2015), berikut ini merupakan perincian dan keterangan dari

\begin{tabular}{|c|c|}
\hline Unsur & Formula \\
\hline DSR & $\frac{(\text { Receivable } t / \text { Sales } t)}{(\text { Receivable } t-1 / \text { Sales } t-1)}$ \\
\hline GMI & $\frac{(\text { Sales t }-1-\text { COGS t-1)/Sales t-1 }}{(\text { Sales } \mathrm{t}-\mathrm{COGS} \mathrm{t}) / \text { Sales } \mathrm{t}}$ \\
\hline AQI & $\frac{(1-((\text { Current Asset } t+\text { PPE } t) / \text { Total Asset } t))}{(1-((\text { Current Asset } t-1+\text { PPE t-1)/Total Asset } t-1))}$ \\
\hline SGI & $\frac{\text { Sales t }}{\text { Sales t-1 }}$ \\
\hline DEPI & $\frac{(\text { Depreciation } \mathrm{t}-1 /(\text { Depreciation } \mathrm{t}-1+\mathrm{PPE} \mathrm{t}-1))}{(\text { Depreciation } \mathrm{t} /(\text { Depreciation } \mathrm{t}+\text { PPE } \mathrm{t}))}$ \\
\hline SGAI & $\frac{(\text { SGA expenses } t / \text { Sales } t)}{(\text { SGA expenses } t-1 / \text { Sales } t-1)}$ \\
\hline ACCRUAL & $\begin{array}{l}\text { (Change in Working Capital t- Change in Cash - Change in Tax } \\
\frac{\text { Payable } \mathrm{t}+\text { Depr \& Amortization } \mathrm{t})}{\text { Total Assets } \mathrm{t}}\end{array}$ \\
\hline LEVI & $\frac{((\text { LTD t }+ \text { Current Liabilites t }) / \text { Total Assets } t)}{((\text { LTD t- } 1+\text { Current Liabilites t- } 1) / \text { Total Assets t- } 1)}$ \\
\hline
\end{tabular}
Model Beneish:

\section{Variabel Independen}

\section{Tekanan}


Faktor tekanan yang digunakan dalam penelitian ini diproksikan menggunakan stabilitas Keuangan. Stabilitas keuangan adalah suatu situasi atau kondisi dimana keuangan perusahaan dalam kondisi stabil. Stabilitas keuangan diproksikan dengan tingkat pertumbuhan aktiva (AGROW). AGROW menggunakan skala rasio dengan rumus sebagai berikut (Martantya dan Daljono, 2013):

$$
\text { AGROW }=\frac{\text { Total aset } \mathrm{t}-\text { total aset } \mathrm{t}-1}{\text { Total aset } \mathrm{t}} \times 100 \%
$$

\section{Target Keuangan}

Target keuangan dalam penelitian ini diproksikan dengan ROA, ROA digunakan untuk mengukur kemampuan perusahaan dalam memperoleh laba dari asset yang digunakan. ROA menggunakan skala rasio. Adapun rumus ROA sebagai berikut:

$$
\mathrm{ROA}=\frac{\text { Laba setelah pajak } \mathrm{t}-1}{\text { Total aset } \mathrm{t}-1}
$$

\section{Kesempatan}

Faktor kesempatan diukur dengan keefektifan pengawasan, dengan penjelasan singkat di bawah ini: Efektivitas Pengawasan. Efektivitas pengawasan dalam suatu perusahaan tergambarkan lewat peran komisaris independen. Oleh karena itu, efektivitas pengawasan diproksikan dengan proporsional jumlah anggota komisaris independen dengan jumlah anggota dewan komisaris menyeluruh (IND) dan IND mengunakan skala rasio.

\section{Rasionalisasi}

Faktor rasionalisasi diukur dengan menggunakan total akrual, dengan penjelasan di bawah ini:Total Akrual. Total akrual menggunakan skala rasio. Rumus Total Akrual sebagai berikut:

\section{TACC $=$ Net Income - Cash Flow from Operating Activities}

\section{Variabel Kontrol}

\section{Ukuran perusahaan}

Ukuran perusahaan diukur dengan menggunakan total asetnya. Dalam penelitian Lou dan Wang (2009), nilai total asset ditransformasikan ke dalam proses logaritma sebagai variabel pengendali.

\section{Populasi dan Sampel}

Populasi yang digunakan dalam penelitian ini adalah perusahaan infrastruktur, ulititas, dan transportasi yang terdaftar di BEI dari tahun 2012-2014. Metode yang digunakan purposive sampling, dengan kriteria sebagai berikut, (1) Perusahaan secara konsisten terdaftar sebagai perusahaan konstruksi \& infrastruktur, utilitas, telekomunikasi dan transportasi di website IDX atau website perusahaan pada tahun 2012-2014; (2) Perusahaan menggunakan mata uang rupiah sebagai standar mata keuangan dalam laporan keuangannya dari tahun 2012-2014; (3) Perusahaan memiliki data audited per 31 Desember yang dibutuhkan dalam penelitian dari tahun 2012-2014; (4) Perusahaan diklasifikasikan 1 yaitu melakukan Fraudulent financial statement jika memiliki index beneish diatas -2.22 dan diklasifikasikan 0 yaitu tidak melakukan Fraudulent financial statement jika dibawah -2.22.

\section{Metode Analisis}


Pengujian hipotesis dalam penelitian ini dapat digambarkan dengan menggunakan persamaan di bawah ini:

$$
\text { FRAUD }=\alpha+\beta 1 . \text { AGROW }+\beta 2 . R O A+\beta 3 . I N D+\beta 4 . \text { TACC }+\beta 5 . \mathrm{SIZE}+\varepsilon
$$

Keterangan:

$\begin{array}{ll}\text { FRAUD } & \text { : Kecurangan dalam laporan keuangan } \\ \text { A } & : \text { Konstanta } \\ \beta & \text { : Koefisien Variabel } \\ \text { AGROW } & : \text { Tingkat Pertumbuhan Aset } \\ \text { ROA } & : \text { Return On Asset }(\text { ROA) } \\ \text { IND } & \text { : Proporsi Dewan Komisaris Independen } \\ \text { TACC } & : \text { Total Akrual } \\ \text { SIZE } & : \text { Transformasi logaritma natural }(\mathrm{Ln}) \text { dari total aset perusahaan i } \\ & \text { pada tahun t } \\ \varepsilon & : \text { Error }\end{array}$

\section{HASIL DAN PEMBAHASAN}

Penelitian ini menggunakan objek penelitian yang mengarah pada perusahaan konstruksi, infrastruktur, transportasi dan telekomunikasi yang terdaftar di BEI pada tahun 2012 - 2014. Berdasarkan model beneish (model yang digunakan dalam mengindentifikasi perusahaan yang terindikasi fraud), ditemukan sebanyak 39 perusahaan yang terindikasi melakukan fraud dan 57 perusahaan yang tidak terindikasi melakukan fraud selama tahun 2012-2014. Metode pemilihan sampel yang digunakan adalah purposive sampling (metode pemilihan sampel yang didasarkan pada kriteriakriteria tertentu).

Tabel 3.1

Populasi dan Sampel Penelitian

\begin{tabular}{lcc}
\hline \multicolumn{1}{c}{ Kriteria Sampel } & $\begin{array}{c}\text { Jumlah } \\
\text { Sampel } \\
\text { per Tahun }\end{array}$ & $\begin{array}{c}\text { Total } \\
\text { Sampel }\end{array}$ \\
\hline $\begin{array}{l}\text { Perusahaan secara konsisten terdaftar sebagai } \\
\text { perusahaan konstruksi \& infrastruktur, utilitas, } \\
\text { telekomunikasi dan transportasi di website IDX atau } \\
\text { website perusahaan pada tahun 2012-2014 }\end{array}$ & 58 & 174 \\
$\begin{array}{l}\text { Perusahaan menggunakan mata uang selain rupiah } \\
\text { sebagai standar mata keuangan dalam laporan } \\
\text { keuangannya dari tahun 2012-2014. }\end{array}$ & $(24)$ & $(72)$ \\
$\begin{array}{l}\text { Perusahaan tidak memiliki data audited per 31 } \\
\text { Desember yang dibutuhkan dalam penelitian dari } \\
\text { tahun 2012-2014. }\end{array}$ & & \\
$\begin{array}{l}\text { Perusahaan yang dijadikan sampel } \\
\text { Perusahaan diklasifikasikan 1 yaitu melakukan }\end{array}$ & & \\
$\begin{array}{l}\text { Fraudulent financial statement jika memiliki index } \\
\text { beneish diatas -2.22 }\end{array}$ & & \\
Perusahaan diklasifikasikan 0 yaitu melakukan & & 39 \\
& & \\
\end{tabular}


Fraudulent financial statement jika memiliki index

beneish dibawah -2.22

Total sampel akhir

96

Sumber: data yang dikumpulkan

Tabel 4.1

Statistik Deskriptif Perusahaan Tahun 2012-2014

Descriptive Statistics

\begin{tabular}{|l|r|r|r|r|r|r|r|}
\hline & $\mathrm{N}$ & \multicolumn{1}{|c|}{ Range } & $\begin{array}{r}\text { Minimu } \\
\mathrm{m}\end{array}$ & $\begin{array}{r}\text { Maximu } \\
\mathrm{m}\end{array}$ & \multicolumn{1}{c|}{ Mean } & $\begin{array}{c}\text { Std. } \\
\text { Deviation }\end{array}$ & Variance \\
\hline FFS & 96 & 1 & 0 & 1 &, 41 &, 494 &, 244 \\
AGROW & 96 & 2,41 & $-1,89$ &, 52 &, 0834 &, 28253 &, 080 \\
ROA & 96 &, 78 &,- 38 &, 40 &, 0265 &, 13694 &, 019 \\
Kepemili & & & & & & & \\
kan & & & & & & & \\
Komisari & 96 &, 63 &, 17 &, 80 &, 4199 &, 12349 &, 015 \\
s & & & & & & & \\
Independ & & & & & & & \\
en & & & & & & & \\
Total & 96 & 65849887 & 3454500 & 1304887 & 13988352 & 23385,46 & 21101868 \\
Accrual & & 605398 & 0000000 & 605398 & 30655,91 & 7 & 0000000 \\
Firm Size & 96 & 9,44 & 23,14 & 32,58 & 28,6918 & 1,97555 & 3,903 \\
Valid N & 96 & & & & & & \\
(listwise) & & & & & & & \\
\hline
\end{tabular}

Sumber: Hasil perhitungan IBM SPSS 21.0

Dari tabel di atas, dapat simpulkan bahwa total sampel untuk penelitian ini adalah sejumlah 96 sampel. Statistik deskriptif amat berguna bagi suatu penelitian dalam menggambarkan data minimum, maximum, mean, standard deviation, dan variance dari masing-masing variabel yang digunakan di dalam penelitian.

\section{Uji Tingkat Ketepatan Prediksi Model}

Ada 57 perusahaan diprediksi mengalami non fraudulent financial statement tetapi hanya 42 perusahaan yang tepat diprediksi non fraudulent financial statement dan 15 perusahaan yang diprediksi fraudulent financial statement. Sebanyak 39 perusahaan yang diprediksi mengalami fraudulent financial statement tetapi hanya 22 perusahaan yang tepat diprediksi fraudulent financial statement dengan nilai persentase sebesar 56,4\% dan sisanya sebanyak 17 perusahaan diprediksi secara salah mengalami fraudulent financial statement. Gambaran analisis atas variabel tersebut disajikan pada tabel 4.2 berikut ini:

Tabel 4.2

Persentase Fraud Pada Laporan Keuangan Perusahaan Tahun 2012-2014 Classification Table ${ }^{\mathrm{a}}$

\begin{tabular}{|l|l|l|}
\hline \multirow{2}{*}{ Observed } & \multicolumn{2}{|c|}{ Predicted } \\
\cline { 2 - 3 } & FFS & Percentage \\
\hline
\end{tabular}




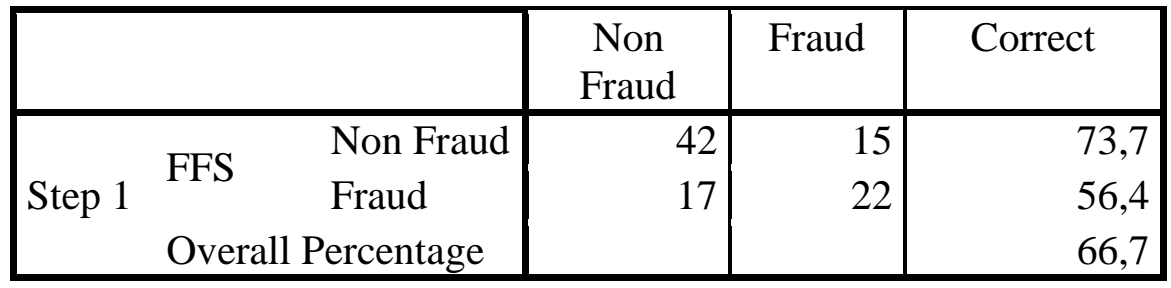

Sumber: Hasil perhitungan IBM SPSS 21.0

\section{Uji Kelayakan Model dan Hipotesis}

\section{Uji Kelayakan Model}

Dalam menilai model yang akan digunakan di dalam suatu penelitian, uji kelayakan model (goodness of fit test) patut dilakukan untuk mengetahui model tersebut cocok atau tidak. Hasil yang diperoleh dari uji kelayakan yang dilakukan melalui uji hosmer and lemeshow menunjukkan bahwa nilai yang di dapat lebih besar dari tingkat signifikansi $(0,164>0,05)$. Angka tersebut menunjukkan bahwa model yang dihipotesiskan sebelumnya dapat digunakan atau cocok untuk penelitian ini.Gambaran hasil tersebut dapat dilihat pada tabel 4.3 berikut ini:

\section{Tabel 4.3}

Uji Kelayakan Model (Goodness of Fit Test)

Hosmer and Lemeshow Test

\begin{tabular}{|l|r|r|r|}
\hline Step & Chi-square & \multicolumn{1}{c|}{ df } & \multicolumn{1}{c|}{ Sig. } \\
\hline 1 & 11,716 & 8 &, 164 \\
\hline
\end{tabular}

\section{Uji Kelayakan Keseluruhan Model}

Uji ini berbeda dengan uji kelayakan yang dilakukan sebelumnya. Sebab, uji kelayakan ini lebih menggambarkan ketepatan model regresi logistik dengan hasil data diperoleh. Uji statistik yang dilakukan didasarkan pada fungsi likelihood, yaitu -2 loglikelihood. Hasil uji kelayakan keseluruhan model digambarkan pada tabel 4.4 dan tabel 4.5 berikut ini:

Tabel 4.4

Step 0: Uji Kelayakan Keseluruhan Model - Chi Square Test Iteration History ${ }^{\mathrm{a}, \mathrm{b}, \mathrm{c}}$

\begin{tabular}{|ll|r|r|}
\hline Iteration & \multicolumn{1}{|c|}{$\begin{array}{c}-2 \text { Log } \\
\text { likelihood }\end{array}$} & $\begin{array}{c}\text { Coefficient } \\
\text { s }\end{array}$ \\
\cline { 3 - 4 } & & & Constant \\
\hline Step 0 & 2 & 129,690 &,- 375 \\
& 3 & 129,689 &,- 379 \\
& 3 & 129,689 &,- 379 \\
\hline
\end{tabular}

Sumber: Hasil perhitungan IBM SPSS 21.0

Tabel 4.5

Step 1: Uji Kelayakan Keseluruhan Model - Chi Square Test Iteration History ${ }^{\mathrm{a}, \mathrm{b}, \mathrm{c}, \mathrm{d}}$

\begin{tabular}{|l|l|l|}
\hline Iteration & $-2 \log$ & Coefficients \\
\cline { 2 - 3 }
\end{tabular}




\begin{tabular}{|c|c|c|c|c|c|c|c|c|}
\hline & & $\begin{array}{c}\text { likelihoo } \\
\mathrm{d}\end{array}$ & $\begin{array}{c}\text { Consta } \\
\text { nt }\end{array}$ & X1 & $\mathrm{X} 2$ & X3 & $\mathrm{X} 4$ & Z \\
\hline \multirow{8}{*}{ Step 1} & 1 & 111,248 & $-4,532$ & ,374 & 2,831 & - & ,000 & ,202 \\
\hline & & 109618 & $-6,822$ & .468 & 4,063 & - & 000 & .285 \\
\hline & 2 & & & & & 4,128 & & \\
\hline & 3 & 109,514 & $-7,502$ & ,468 & 4,371 & & , 000 & ,308 \\
\hline & & & & & & 4,120 & & \\
\hline & 4 & 109,514 & $-7,539$ & ,467 & 4,384 & & ,000 & ,309 \\
\hline & & & & & & 4,118 & & \\
\hline & 5 & 109,514 & $-7,539$ & ,467 & 4,384 & 4,118 & ,000 & ,309 \\
\hline
\end{tabular}

Sumber: Hasil perhitungan IBM SPSS 21.0

Pengujian pada step 0 menunjukkan bahwa angka dari -2 log likelihood adalah sebesar 129,689 dan pada step 1 adalah sebesar 109,514. Sehubungan dengan uji ini menggunakan Chi Square Test, maka nilai df pada step 0 adalah sebesar 118,75161 dan nilai df pada step 1 adalah sebesar 114,26787. Angka tersebut menunjukkan bahwa model penelitian yang dilakukan uji kelayakan keseluruhan pada step 0 tidak fit $(129,689>118,75161)$.Lalu, untuk uji kelayakan keseluruhan pada step 1 menunjukkan bahwa model pada penelitian fit $(109,514<114,26787)$. Hal ini berarti bahwa variabel independen (bebas) yang ditambahkan ke model dapat dalam memperbaiki model penelitian menjadi fit.

\section{Uji Cox and Snell's RSquare dan Nagelkerke's R Square}

Uji ini sama seperti uji koefisien determinasi pada umumnya, yaitu uji yang digunakan untuk mengetahui seberapa jauh variabel dependen (terikat) dapat dijelaskan oleh variabel independen (bebas). Hasil yang diperoleh untuk penelitian ini adalah bahwa sebesar 25,6\% variabel dependen dapat dijelaskan oleh variabel independen dan sisanya sebesar 74,4\% dapat dijelaskan oleh faktor-faktor lain yang tidak dimasukkan ke dalam model regresi. Hasil dari uji cox and snell's $R$ square dan nagelkerke's $R$ square dapat dilihat pada tabel 4.6 sebagai berikut:

Tabel 4.6

Uji Cox and Snell's RSquare dan Nagelkerke's $R$ Square Model Summary

\begin{tabular}{|l|c|c|c|}
\hline Step & $\begin{array}{c}-2 \text { Log } \\
\text { likelihood }\end{array}$ & $\begin{array}{c}\text { Cox \& Snell } \\
\text { R Square }\end{array}$ & $\begin{array}{c}\text { Nagelkerke R } \\
\text { Square }\end{array}$ \\
\hline 1 & $109,514^{\mathrm{a}}$ &, 190 &, 256 \\
\hline
\end{tabular}

Sumber: Hasil perhitungan IBM SPSS 21.0

\section{Uji Signifikansi Koefisien}

Uji hipotesis yang dilakukan di dalam penelitian ini adalah model regresi logistik. Uji signifikansi di dalam model regresi logistik ditujukan untuk menguji pengaruh yang terjadi antara variabel independen (AGROW, ROA, kepemilikan komisaris independen, dan total akrual) terhadap variabel dependen (fraudulent financial statement) dengan variabel control (firm size) sebagai variabel penengah. Hasil yang diperoleh dari pengujian ini adalah hanya kepemilikan komisaris 
independen yang memiliki pengaruh yang signifikan terhadap fraudulent financial statement $(0,044<0,05)$. Lalu, untuk AGROW $(0,664)$, ROA $(0,062)$, dan total akrual $(0,060)$ tidak memiliki pengaruh yang signifikan terhadap fraudulent financial statement dikarenakan memiliki nilai signifikansi lebih besar dari tingkat signifikansi atau keyakinan $(0,05)$. Untuk variabel kontrol yang merupakan penengah dari variabel independen dan dependen pun juga tidak memiliki pengaruh yang signifikan terhadap fraudulent financial statement $(0,074>0,05)$.

Dari hasil yang diungkapkan di atas, dapat disimpulkan bahwa walaupun perusahaan memiliki ruang lingkup usaha yang besar, sedang, ataupun kecil, apabila pengawasan yang dilakukan oleh pihak independen di dalam perusahaan, seperti komisaris independen lemah, maka dapat dipastikan perusahaan tersebut akan melakukan fraudulent financial statement dengan maksud untuk mencapai suatu tujuan tertentu. Hasil regresi atau pengaruh yang terjadi dapat dilihat pada tabel 4.7 berikut ini:

Tabel 4.7

Uji Signifikansi Koefesien- Regresi Logistik Variables in the Equation

\begin{tabular}{|rl|r|r|r|r|r|r|}
\hline & \multicolumn{1}{|c|}{ B } & \multicolumn{1}{c|}{ S.E. } & Wald & df & \multicolumn{1}{c|}{ Sig. } & \multicolumn{1}{c|}{$\operatorname{Exp}(\mathrm{B})$} \\
\hline & X1 &, 467 & 1,076 &, 189 & 1 &, 664 & 1,596 \\
X2 & 4,384 & 2,348 & 3,486 & 1 &, 062 & 80,195 \\
Step 1 & X3 & $-4,118$ & 2,044 & 4,060 & 1 &, 044 &, 016 \\
& X4 &, 000 &, 000 & 3,544 & 1 &, 060 & 1,000 \\
Z &, 309 &, 173 & 3,191 & 1 &, 074 & 1,362 \\
Constant & $-7,539$ & 4,929 & 2,340 & 1 &, 126 &, 001 \\
\hline
\end{tabular}

a. Variable(s) entered on step 1: X1, X2, X3, X4, Z.

Sumber: Hasil perhitungan IBM SPSS 21.0

\section{SIMPULAN}

Berdasarkan analisis data yang telah dilakukan, dapat diambil kesimpulan bahwa, (1) Variabel kesempatan yang diukur atau diproksikan dengan kepemilikan komisaris independen memiliki pengaruh yang signifikan terhadap kecurangan dalam laporan keuangan $(0,044<0,05)$. Hasil ini sesuai dengan penelitian Skousen et al. (2009); (2) Variabel tekanan yang diukur dengan AGROW (0,664>0,05), tidak memiliki pengaruh yang signifikan terhadap kecurangan dalam laporan keuangan. Hal ini bertentangan dengan hasil yang dilakukan oleh Martantya dan Daljono (02:2013) serta Skousen et al. (2009); (3) Target keuangan yang diukur dengan ROA $(0,062>0,05)$ tidak memiliki pengaruh yang signifikan terhadap kecurangan dalam laporan keuangan. Hal ini tidak sesuai dengan hasil - hasil penelitian Nugraha dan Henny (02:2015), Diany dan Ratmono (03:2014). dan Martantya dan Daljono (02:2013); (4) Rasionalisasi yang diukur dengan Total Akrual $(0,060>0,05)$ juga tidak memiliki pengaruh yang signifikan terhadap kecurangan dalam laporan keuangan. Hasil ini sesuai dengan penelitian Ardiyani dan Utaminingsih (2015).

\section{Keterbatasan}


Adapun keterbatasan dalam penelitian ini dapat dijabarkan sebagai berikut. (1) Obyek perusahaan yang diteliti terbatas pada perusahaan konstruksi \& infrastruktur, utilitas, telekomunikasi dan transportasi; (2) Tahun penelitian yang digunakan terlalu terbatas yakni hanya 3 tahun (2012-2014); (3) Adanya keterbatasan sumber dan kajian teori rasionalisasi dalam mendeteksi fraudulent financial statement khususnya mengenai rasionalisasi yang diukur melalui total akrual; (4) Dari Hasil uji yang ada hanya 25,6\% variabel dependen dapat dijelaskan oleh variabel independen.

\section{Saran}

Berdasarkan keterbatasan yang dimiliki pada penelitian ini, peneliti memiliki saran dan harapan pada peneliti-peneliti selanjutnya yang ingin meneliti dengan topik yang sama dengan penelitian ini, yaitu, (1) Obyek penelitian yang digunakan harus diperluas atau diperbesar kembali agar lebih merepresentasikan kondisi sesungguhnya; (2)Tahun penelitian yang digunakan harus lebih panjang dengan tujuan agar hasil pengujian lebih akurat dan tepat; (3) Variabel independen dan variabel kontrol yang digunakan tidak dibatasi dan harus dikembangkan atau diperbanyak, seperti keberadaan divisi internal audit, masa jabatan komite audit, dan kualitas sistem pengendalian intern.

\section{DAFTAR PUSTAKA}

Belkoui, Ahmad. 2007. Teori Akuntansi. Edisi kelima. Jakarta: Salemba Empat Daljono, Martantya. 2013. Pendeteksian kecurangan laporan keuangan melalui faktor risiko

dan peluang. Diponegoro Journal of Accounting. Vol 2, No.2: 1-12

Diany, Yuvita Avrie dan Dwi Ratmono. Determinan kecurangan laporan keuangan: 9 pengujian teori fraud triangle. Diponegoro journal \& accounting. Vol 3, No. 2: 1-

Detikfinance.2015.http://finance.detik.com/read/2015/05/18/104018/2917159/6/saham -inovisi-dibekukan-4-bulan-karena-laporan-keuangan-banyak-salah

Fitrawansyah. 2014. Fraud \& Auditing. Jakarta: Mitra Wacana Media Ghozali, Imam. 2013. Aplikasi analisis multivariate dengan program IBM SPSS 21 Update

PLS Regresi. Cetakan VII. Semarang: Badan PenerbitUniversitas Diponegoro https://inaproc.lkpp.go.id/v3/daftar_hitam Hogan, Chris E., Zabihollah Rezaee, Richard A. Rilley Jr. 2008. Financial statement fraud:

insights from the academic literature. Auditing: A journal of practice \& theory american accounting association. Vol 27, No. 2: 231-252

Lou, Y.I., and M.L.Wang. 2009. Fraud Risk Factor Of The Fraud Triangle Assesing

The LikelihoodOf Fraudulent Financial Reporting. Journal of Business and

Economic Research, Vol. 7, No. 2, p. 62-66.

Mahama, Muntari. 2015. Detecting corporate fraud and financial distress using the altman and beneish models the case of enron corp. International Journal of Economics,

Commerce and Management. Vol 3, No 1: 1-18

Nugraha, Noval Dwi Aditya dan Deliza Henny. 2013. Pendeteksian laporan keuangan No. 1: melalui faktor resiko, tekanan dan peluang. E-journal akuntansi trisakti. Vol 2, 
$29-48$

Radarbanten.2015. http://www.radarbanten.com/read/berita/10/33766/Kok-BisaKontraktor-Gedung-DPRD-Tangsel-Masuk-Daftar-Blacklist-LKPP.html

Skousen, C. J. K. R. Smith and C. J. Wright. 2009. Detecting and predicting financial statement fraud: the effectiveness of the fraud triangle and SAS No. 99.

Corporate 53-81

governance and firm performance advances in financial economics. Vol 13,

Sari, Maylia Pramono Sari dan Sukirman. Model deteksi kecurangan berbasis fraud triangle.

Jurnal akuntansi \& Auditing. Vol 9, No. 2: 199-225

Warshavsky, Mark. 2012. Analyzing Earnings Quality as a Financial Forensic Tool.

Financial Valuation and Litigation Expert Journal. No 39: 16 